\title{
Research on the Construction of Physical Education Think Tank in Colleges and Universities under the Background of Modernization of National Sports Management
}

\author{
Yao Bi \\ Zhuhai College of Jilin University \\ 279399748@qq.com
}

\begin{abstract}
Keywords: College sports think tank; Sports management system; Sports governance construction
\end{abstract}
\begin{abstract}
With the boost of the comprehensively deepening reform process in our country, the state has begun to put the development of the think tank in various fields into the development of key areas. Since the 18th National Congress of the Communist Party of China (CPC), perfecting and developing the socialist system with Chinese characteristics, and advancing the modernization of governance system and governance capacity of the state have been put on the agenda. As an indispensable area of China's modernization construction, the perfection and development of its management system and capacity building for sports will promote the modernization level of Chinese sports effectively. As an important part of the field of sports modernization, the construction of college sports think tank must be valued and pondered by all sectors of society. How to carry out the construction of college sports think tank has become one of the key topics discussed in the background of national sports intellectual modernization.
\end{abstract}

\section{Introduction}

The fact has to be admitted that China's sports construction and development level is far behind that of the western developed countries. Even worse, as one of the areas of sports construction, sports think tank is lack of corresponding development system and governance model. It is self - evident that the important role is played in construction of sports think tank in colleges and universities in promoting the construction of national sports think tanks. How to build a suitable think tank system suitable for the development of college sports in China has become one of the most important problems in the field of physical education and even the whole society. As the construction of physical education think tank in China's universities is still in the early stage of exploration, the relevant knowledge system, system construction and facilities investment are still at a low level, therefore, our country must proceed research combining with their own practical situations, conclude and analyze on the basis of practice, and ultimately to establish a sports think tank system suitable for China's national conditions. On how to carry out the construction of sports think tank, the exploration and research about university sports think tank has undoubtedly played a decisive role.

At the beginning of 2015, the White Paper on "Strengthening the Construction of New Think Tanks with Chinese Characteristics" issued by the General Office of the CPC Central Committee and the State Council mentioned a clear reference to "the construction of a new type of think tank with Chinese characteristics is an important component of the national governance system and modernization of governance capacity. Therefore, the reform of the field of sports must also carry out exploration focusing on "sports management system and management capacity modernization". Although the sports think tank construction of China's university is still in the initial stage, China's abundant human and material resources will be the backbone of the construction of university think tanks. This paper focuses on analyzing the status of college sports think tank construction of our country, makes a summary for the advantages of colleges sports themselves, and finally collects the strategy recommendations on construction of Chinese university sports think tank. 


\section{China's Sports Management System and Management Capacity of the Modernization Drive}

"Promote the modernization of national governance system and governance capacity" becomes a programmatic document to deepen institutional reform in the various sectors of our country since the 18th Third Plenary Session. The sports industry, as one part of it, plays an important role in promoting the implementation of the programmatic document. Strengthening the modernization of sports management system and management ability is the inevitable trend of the times. The realization of this kind of governance system and the modernization of governance ability is helpful to solve the problems in the field of sports in China and promote the development of sports in our country in a more rapid and steady way. Based on different standards, sports governance system and governance ability can be divided into competitive sports governance, sports industry governance, group sports management and other types, so faced with many types of sports industries, China's sports governance model must band together government, society, schools, Industry and so on, to ultimately establish the development of the situation that various sports industries have interrelated relation and mutual cooperation. The construction of university sports think tank will provide strong support for the development of sports think tank in China. Therefore, we must attach great attention to the construction and development of college sports think tank.

\section{The Connotation and Orientation of the Construction of Physical Education Think Tank in Colleges and Universities}

College Sports Think Tank Construction Connotation. "Think tank" is usually said public research institutions are established by scholars from various fields of intellectuals for the leadership planning class of people to provide suggestions and recommendations in the political, economic, cultural, military, national, foreign policy. A sports think tank is included in a professional think tank, and its highest goal is to provide services for sports strategies and responses. The objects that it emphasizes are the form of sports organizations and management methods, and its ultimate goal is to promote innovation in sports reform, and put our country towards the sports power. The sports think tank is divided into the following types: Sports Science Research Institute, Sports Learning Team, Physical Decision-Making bodies, Sports Associations, Universities, Sports News Media and related publishers. The university sports think tank is an important part of the construction of Chinese sports think tank. It has the natural advantages such as the discipline, the talented person, the foreign exchange and the related discussion activity. Therefore, it can become the critical focus research object of the Chinese sports think tank. In areas such as the group sports, sports-related industries and sports competitions, proceeding an in-depth study, with superior human resources and technical services to make a contribution to the management of China's sports and the construction of think tank.

The Orientation of College Sports Construction in China. The orientation of university sports think tank construction includes three aspects: direction orientation, operation implementation orientation and content orientation. Therefore, the construction of university sports think tank should fully takes the three directions into consideration. Therein, the orientation refers to make a rational analysis on the development direction in the beginning of the construction of college sports think tanks in China, and setting out a plan based on the actual situation. The construction of sports think tank in colleges and universities in China should try our best to absorb and understand the general direction and system of governance under the modern background of our reform. Secondly, in the specific aspects of the construction of college sports, we should focus on the actual level of Chinese sports and requirements for the construction and perfection. Operational implementation direction mainly says that the construction process of sports think tank from bureau should be specific and feasible, and the direction is to follow the process of reasonable arrangements for the operation. At the same time, under the conditions of advocation by the rules, we need to think about how to implement that specific operation from the advocation. The orientation of content meaning refers to the collection of three aspects including knowledge, wisdom and wise. Colleges and universities are places where the wise come together, while the good the environment of knowledge 
and research makes more scholars choose to stay in school for further study. Therefore, the university is also the birthplace of wisdom, and the organic integration of these three developments is the inevitable choice of university think tank construction. Taking full use of each college talent advantage, giving them full opportunity to display their talents, at the same time, organizer should combined the wisdom of these intellectual wealth and specific issues, to formulate a reasonable and effective strategy to further improve the think tank project adjustment.

\section{The Advantages of Physical Education Think Tank Construction in Colleges and Universities}

First Is the Support of Science and Technology. There is no doubt that colleges and universities are the ideal place for wisdom and science and technology. Regardless of foreign or domestic, universities will be regarded as the best place for further development of various fields. Many of China's comprehensive universities, normal schools and sports colleges have sports-related research institutions and training base. In addition, many research bases of humanities and social sciences and laboratories have played the role of the sports think tank. This kind of the combination of humanities and social sciences can be, to the greatest extent, providing opportunities and conditions for the construction of sports think tanks. In addition, colleges and universities gather in the humanities, management, law, medicine, psychology and other professional disciplines, where the competing development of various disciplines intangibly provides a unique condition for the construction of university sports think tank. The gathering of experts and scholars not only can provide intellectual support and theoretical support for the construction of sports think tank, but also conducive to the further development of sports think tank. They make a contribution to the final social modernization through sharing the national, social, industry and other areas of experimental research for the country's sports think tank construction. Therefore, we should give full play to the advantage of universities in science and technology to carry out vigorous research and exploration, gradually establishing the development of university sports think tank, and ultimately contributing wisdom for the national sports think tank.

Second Is National Policy Support. The emphasis of country on the construction of think tanks becomes more and stronger in recent two years. The promulgation of a series of laws and regulations for the university think tank construction provides an excellent environment for the construction. Such as "Opinions on the construction of new think tanks with Chinese characteristics", "Opinions on strengthening the construction of new think tanks with Chinese characteristics" and other relevant provisions of the law. This externally favorable development environment provides an excellent environment for the construction of university sports think tank. The great emphasis from the Education Bureau, the National Sports Center and down to sports disciplines of the various regions of the schools, the related sports research institutions and the construction of the practice base provide an excellent environment or the construction of sports think tank.. Tsinghua University, Wuhan Institute of Physical Education, Shenyang Normal University and other higher education institutions have established different types of sports research laboratories and sports projects. These phenomena all add great enthusiasm and vitality to the construction of the sports think tank in our country, and provide the policy direction and external environment guarantee for perfecting the sports think tank.

Talent Wisdom Support. Universities are the best places to gather the wise and researchers, the wisdom of humanities in sports disciplines are also gathered in the major colleges and universities, therefore, this environment will certainly benefit the communication between different teachers and scholars. They can not only discuss and study some of the problems and phenomena conveniently, but also identify problems in time through the information and professional knowledge of researchers. In addition, the research atmosphere of universities can also provide the driving force and environment for the related construction of think tanks, and it is one of the ways to combine teachers and students to carry out scientific research. This kind of atmosphere can maximize the mobilization of the majority of teachers and students to join the enthusiasm of the building of think tanks. While, the sports think tank building is not an exception, where a large number of sports students, physical education teachers team, sports expert-level researchers provides a huge treasure 
trove of knowledge for the construction of sports think-tank .A variety of sports students including undergraduate, postgraduate and doctoral students. The advantage of talent pool contributing to the construction of university sports think tank cannot be compared with other institutions.

Data Resources Support. Today has entered the era of information and data, especially in the recent two years the rising of large data brings enormous challenges for the major industry development, and brings great opportunities as well. The challenges and opportunities faced by the sports industry's large data are the following: First, the big data of the sports industry have embedded into all areas of marketing, so the sports industry will inevitably get the challenge from the big data. How to combine properly the big data with the marketing and the audience of sports products into sports industry must be thought about seriously by people of sports product, which relates to scientific and effective competition and development of the sports industry. In the part of competitive sports, athletes sports equipment Selection, training mode and tailored to develop scientific and rational training programs, all kinds of physical and mental state of the game and the results of the game predictive analysis and so on need to be quantified through the data. This requirement is that the big data become the first choice of competitive sports. The rich database based on the big data provides a very convenient and effective condition for the evaluation of competitive sports. Therefore, with the great data, the further development of competitive sports is just around the corner. The final part are mass sports, the data develop scientific and reasonable sports standards for the masses of sports. Combined with different physical condition of individuals to tailor the fitness program, the greatest degree of improvement of the people's sports literacy and physical and mental health can be reached.

\section{Research on the Construction Strategy of Physical Education Think Tank in Colleges and Universities}

Promote the Integration and Development of Sports and Other Disciplines. The development of the social era makes the integration of other industries development trend emerge no matter that it is competitive sports or sports industry or mass sports and other aspects. Therefore, in the construction of college sports think tank, we must break the single discipline development model to realize the various professional disciplines integrated organically and coordination operation. The establishment and perfection of university think tanks need the integration and development of different disciplines, but the reality of our country is that each subject is still single-disciplinary development, and it can seldom carry out effective joint and harmonious development between different colleges and specialties. Therefore, in the future, when thinking about the construction of university sports think tank, we must integrate the advantages and characteristics of each profession into the construction of sports thin-tank, carrying out the sports dilemma of all-round, comprehensive analysis and exploration by adopting the cross-field approach and different special research angles, to enhance the depth and space of special research.

Change the Role Positioning of the Sports Industry. China sports think tank is defined as the interpretation or propaganda of sports policy often, not as the identity of "wisdom" or "decision makers", to precede the analysis. Therefore, the role positioning of sports is not converted into the role of decision makers, and the function of its sports think tank is not fully tapped and obtained the attention. Therefore, the national society and universities must pay attention to the importance of sports think tank, making a reasonable change and adjustment for the role. The first is a breakthrough from the ideological aspects. Strengthen the problem-oriented, re-position and review the actual needs standard of sports reform, and change the "role of publicity" to the "decision-making role". The second way is a breakthrough of mode. The construction of sports think tank not only needs the guidance of professional think tank knowledge, but also needs the sports research team to carry out investigation and study thoroughly, conduct full investigation and practice on mass sports, competitive sports and other industries. The combination of the theory and practice can figure out the problems to the maximum extent and can effectively find out effective solutions. The third method is a breakthrough of method. This research method mainly is to be able to turn the research methods into the orbit of the combination of the large data, Relying on the 
advantages of scientific research institutions, laboratories, information collection advantages to create the excellent environment for an efficient sports think tank, we provide data platform for the sports industry to facilitate support, And ultimately provide scientific and effective intellectual support for the relevant government policy-making..

Advocate Open Operation Guide. This concept is to advocate the sharing of advantage resources from the sports information and sports to share and analyze the information in different disciplines and colleges. On the other hand, we also need to achieve cross-industry exchanges and integration between sports and other sectors of the industry, and strengthen the exchange and sharing between China and the world sports power. Through this kind of open operation orientation, we can stimulate the enthusiasm of the sports field to the greatest extent, and greatly improve the space and opportunity of sports development. The integration and exchange of different areas and platforms can effectively find and overcome the negatively unfavorable factors, learn the advantages from other industry fields. And ultimately apply the wisdom wealth of various fields to the construction of the sports think tank.

\section{Conclusions}

As an important part of realizing the modernization of governance system and management ability in our country, the importance of construction of university sports think tank is self-evident. But the current situation of the development of college sports think tank status in the initial stage must attach importance of all sectors of the construction of sports think tanks. The construction of sports think tank holds the natural advantage and resource, therefore, it is necessary to fully utilize the resources of these talents and discipline policy, making use of the advantage of big data, promoting the communication and interaction between different disciplines and fields, and ultimately enhancing the decision - making role of sports think tank, to make a contribution to promote China's sports undertakings and the construction of country's modernization.

\section{References}

[1] Yi Jiandong, Ren Huitao. Study on the construction of chinese sports think tank. Acta Metallurgica Sinica, 2015, 49 (7): 5-13.

[2] Yang Hua. Deepen the reform of sports to promote sports management system and governance capacity modernization. Journal of Beijing Sport University, 2015, 38 (1): 1-7.

[3] Liu Panpan. Sports think tank construction and sports management system and modernization of governance capacity. Journal of Physical Education, 2015, 22 (1): 19-22.

[4] Gu Yanfeng. The path analysis of Chinese universities think tank construction. China University of Science and Technology, 2014, 39 (6): 76-79.

[5] Jiang Nan, Chen Hong. Study on the construction of university sports think tank under the background of national sports management modernization. Acta Metallurgica Sinica, 2016, (09): 23-25. 